\title{
EDUCAÇÃO \& TDIC'S DEMOCRATIZAÇÃO, INCLUSÃO DIGITAL E O EXERCÍCIO PLENO DA CIDADANIA
}

\author{
Aline Canuto de Abreu Santana ${ }^{1}$ \\ Elisângela Alves Pinto ${ }^{2}$ \\ Maria Lucia Bezerra Meireles ${ }^{3}$ \\ Mariele de Oliveira ${ }^{4}$ \\ Renata Ferreira Munhoz ${ }^{5}$ \\ Rosane Saraiva Guerra ${ }^{6}$
}

RESUMO: Em um mundo pós covid, entramos em uma nova era da educação e não há espaço para retrocessos. Nesse sentido, é inegável a necessidade de ressignificação dos profissionais e ajustes à realidade digital, na qual o poder de uma boa formação proporciona novos papeis no constructo docente e na postura discente. Mais do que nunca, torna-se imprescindível uma capacitação significativa, contextualizada com os interesses de uma geração imersa no mundo digital. Não obstante, é vital que haja um exercício docente mediador, que proporcione a democratização, a inclusão e o exercício pleno da cidadania. Nesse sentido, o presente trabalho aborda temáticas concernentes com tais questões para a prática didática digital plena, sem perder de vista o desenvolvimento de capacitações cognitivas, intra e interpessoais exigidas do profissional do presente século, bem como o imprescindível papel dos governantes, no sentido de proporcionar uma reestruturação educacional a fim de transformarmos as múltiplas realidades existentes nas instituições de ensino e na sociedade, em geral. Para a elaboração deste Artigo, foi feita

\footnotetext{
' Docente na Área de Línguas Estrangeiras e Língua Portuguesa e suas Literaturas. Licenciatura Plena em Letras (Português / Inglês / Espanhol).Formações: Google for Education. Pós graduações Lato Sensu: Gestão Escolar e Coordenação Pedagógica, Língua Portuguesa, Literatura Portuguesa e Brasileira. Mestranda em Tecnologias Emergentes em Educação - Must University / Florida - USA. E-mail: alineabreusantana@yahoo.com.br

2 - Docente na área de Língua Portuguesa e Diretora Geral. Licenciatura Plena em Letras (Português / Inglês). Formações: Coaching Multidimensional de Habilidades Psicológicas, Psicopatologia e Psicoterapia Cognitiva Comportamental. Pós graduações Lato Sensu: Gestão Escolar e Coordenação Pedagógica, Aprendizagem Ativa e Tecnologias Educacionais, NeuroEducação e Docência do Ensino Superior. Mestranda em Tecnologias Emergentes em Educação - Must University / Florida - USA.E-mail: elisagouveia@hotmail.com

${ }^{3}$ Assistente Social. Assistente técnica de projetos habitacionais. Docente na área de Educação a distância - Tutora EAD e Presencial do Curso de Serviço Social;

Bacharelada em Serviço Social. Pós graduações Lato Sensu : Gestão de Políticas Públicas e Saúde da família, Gestão e Metodologias da Educação a distância, Gestão de políticas públicas em Gênero e Raça-UFMS; Mestranda em Tecnologias Emergentes Em Educação-Must University/Flórida-USA

E-mail: socialmalub@gmail.com.

4 - Docente na Educação Infantil. Licenciatura em Pedagogia . Graduanda em Artes Visuais. Pós graduação Lato Sensu: Ensino Lúdico. Pós Graduanda Lato Sensu: Atendimento Educacional Especializado Mestranda em Tecnologias Emergentes em Educação-Must University / Florida - USA. E-mail: maryelle.oliveira@hotmail.com.

${ }^{5}$ Docente na Área de Língua Portuguesa . Licenciatura Plena em Letras (Português / Alemão / Inglês). Pós graduação Lato Sensu: Ensino de Português Língua Não Materna - Universidade de Coimbra. Pós graduações Strictu Sensu : Mestrado, Doutorado e Pós-Doutorado em Língua Portuguesa - USP.E-mail: renatafmunhoz@gmail.com.

${ }^{6}$ Docente na área de Geografia. Licenciatura Plena em Geografia. Pós graduação Lato Sensu: Metodologia Inovadoras Aplicadas à Educação: Ensino de Ciências Humanas. Mestranda em Tecnologias Emergentes em Educação - Must University / Florida - USA. E-mail: rosaneguerraoı@gmail.com
} 
uma pesquisa bibliográfica qualitativa, com ênfase na observação e estudo documental, objetivando analisar o cenário educacional previsto em nosso horizonte, após um período calamitoso instaurado mundialmente. Ao mesmo tempo, também procuramos promover um necessário cruzamento dos levantamentos das pesquisas bibliográficas apontadas nas Referências Autorais.

Palavras-chave: Educação. TDIC's. Inclusão. Democratização. Cidadania.

ABSTRACT: In a post covid world, we have entered a new era of education and there is no room for setbacks. In this sense, it is undeniable that professionals need to reframe and adjust to the digital reality, in which the power of a good education provides new roles in the teaching construct and in the student attitude. More than ever, significant training is essential, contextualized with the interests of a generation immersed in the digital world. Nevertheless, it is vital that there is a teaching mediator exercise, which provides democratization, inclusion and the full exercise of citizenship. In this sense, this work addresses issues related to such issues for full digital didactic practice, without losing sight of the development of cognitive, intra- and interpersonal skills required of the professional of the present century, as well as the essential role of rulers, in the sense of provide an educational restructuring in order to transform the multiple realities existing in educational institutions and in society in general. For the elaboration of this article, a qualitative bibliographic research was carried out, with emphasis on observation and documental study, aiming to analyze the educational scenario foreseen in our horizon, after a calamitous period established worldwide. At the same time, we also seek to promote a necessary cross-referencing of bibliographic research surveys pointed out in the Author's References.

Keywords: Education. TDIC's. Inclusion. Democratization. Citizenship.

\section{INTRODUÇÃO}

Se há algo de positivo que podemos destacar nesse caos pandêmico que estamos imersos desde 2020, foi a imensa lupa que nos permitiu enxergar os problemas educacionais em que nos encontrávamos e a necessidade que tínhamos de criarmos soluções para possibilitarmos a inclusão, a equidade e a mudança das injustas realidades. Nesse sentido, é inegável a vital necessidade de transformarmos os múltiplos contextos existentes e que persistem em causar desigualdades socioeconômicas.

Nesse compasso, o enclausuramento nos possibilitou enxergar nas TDICs uma chance em potencial para o exercício pleno da cidadania, desde que autoridades e principais responsáveis pelas transformações sociais tenham a vital consciência de que é possível mudarmos a realidade marginal de vida que milhões de cidadãos são obrigados a enfrentar.

Nesse viés, é de suma importância que os profissionais procurem ressignificar-se, ajustando-se na realidade digital e se permitam à uma ampla reflexão sobre a digipedagogia 
(termo relativamente novo que faz referência à Pedagogia Digital). Para tanto, é preciso que ele esteja aberto a superar limitações e também a promover uma educação acessível e integrada.

Abrir-se para as possibilidades pedagógicas digitais permite ao docente alcançar o perfil do aluno da nova era. Afinal, não se pode olvidar que as necessidades do aprendiz contemporâneo são muito diferentes, pois eles necessitam de uma extensão de sua realidade interativa com os recursos digitais. Conforme JENKINS (2008) afirma: "Ser educado hoje em um entorno escolar desconectado da vida cotidiana é frustrante para qualquer aluno ou aluna".

Essa frustração mencionada acima é produto de décadas na prevalência de um estilo arbitrário educacional. Por anos criou-se entre professores e alunos um enorme abismo relacional e esse fator foi/é a causa da preponderância de necessárias interferências no processo de ensino-aprendizagem. Sendo assim, professores precisam analisar melhor o chão da escola e suas múltiplas possibilidades, pois os alunos alteraram seu jeito e vontade de aprender. Consequentemente, a práxis educacional moderna requer que o professor vá ao encontro do aluno e não o oposto, como sempre ocorreu no estilo tradicional educacional.

No passado, os alunos tinham que se adaptar aos métodos dos professores, mas atualmente o professor deve procurar ir ao encontro dos interesses e da linguagem dos alunos, sendo flexível [...] (JESUS, 2008, p.22).

Sendo necessário esse movimento de ir ao encontro dos interesses discentes, é inegável que devemos, então, utilizar como instrumentos pedagógicos os recursos que fazem parte da sua zona de realidade vivida. Dessa forma, ao praticar a digipedagogia inovadora, o professor se aproxima da linguagem tecnológica dos alunos, tornando possível um espaço interrelacional, e fazendo do ensino algo mais prazeroso e contextualizado. Apesar de serem grandes os desafios, Prudêncio, Carvalho e Ferrira (2007), asseguram que são inúmeras as possibilidades de exploração do espaço virtual, bem como a potencialização da aprendizagem.

Outrossim, temos consciência que muitos lares não dispõem de aparelhos ou até mesmo serviço de internet para acessarem plataformas digitais. Paradoxalmente, devemos nos conscientizar que a tecnologia não é um recurso que se opõe aos mais pobres pois, antes, devemos encará-la como oportunidade de maior capacitação e cabe ao governo 
viabilizar o acesso. Especialmente no Brasil, carecemos da implantação de projetos, leis regularizadoras e verbas que sejam destinadas para que famílias mais humildes tenham as mesmas possibilidades que a geração Ioo\% conectada das classes mais abastadas.

Não somente os mais carentes, mas também os responsáveis por portadores de deficiência lutam há tempos por uma modalidade educativa opcional facilitadora, que lhes permitam lutar pela equidade. Para além da simples preferência metodológica, o ensino virtual é uma necessidade para milhões de aprendizes, que precisam desse tipo de educação diferenciada, seja por questões sociais, fisiológicas ou neurológicas, pois muitos são os que não se encaixam no perfil de alunos considerados dentro do padrão tradicional da sociedade e sofrem de diversas formas, ao serem submetidos ao estilo presencial obrigatório.

Cabe ainda ratificar que não se pode mais conceber a educação sem a intervenção das Tecnologias de Informação. Por isso, é vital que os profissionais da educação estejam mais preparados para lidar com a conjuntura social, viabilizando uma aprendizagem que remeta ao gosto e perfil individual, estimulando o uso das tecnologias para uma melhor compreensão e atuação no mundo.

No compasso dessa reflexão, cabe aos docentes adotarem uma emergencial redefinição da atuação pedagógica e uma visão clara do contexto hodierno tecnológico no qual estamos imersos. Da mesma forma, o educador deve entender o papel que as tecnologias ocupam na educação, para que haja um uso consciente e responsável. Almeida \& Prado (2006) também afirma que é preciso superar o uso ingênuo dessa tecnologia, para que seja possível conhecer as novas formas de aprender e ensinar, além de produzir conhecimentos que são possibilitados através desses recursos e que favorecem a democracia e a integração social.

\section{VIABILIZAÇÃO DA DEMOCRATIZAÇÃO DO CONHECIMENTO}

Podemos inferir que há muitos desafios na educação relacionados à chamada sociedade do conhecimento. Diante disso, qual é o papel da sala de aula ao adequar-se aos novos moldes de ensino? Precisamos definir alguns termos relacionados a este processo.. Há uma diferença entre informação e conhecimento. São denominações de conceitos diferentes que se complementam dentro da estrutura de aprendizagem. Informação são dados adquiridos com significado ou valor agregado, por exemplo, obter dados de quando e 
como algum movimento histórico aconteceu. O conhecimento é a informação organizada por pessoas e recursos, tornando possível o compartilhamento de experiências e diversas interpretações. Entender esta diferença, dentro da educação e no processo de aprendizagem, é muito importante para que se haja democratização do conhecimento dentro do âmbito escolar.

Há pelo menos vinte anos, começa-se o processo de democratização do acesso ao conhecimento. A internet inaugurou uma sociedade chamada sociedade da informação (quando ainda não se tinha rede social) que logo se transformaria em sociedade do conhecimento. Com a rede social, há o aparecimento de um banco de dados e pessoas discutindo todos os tipos de questões diversas, simultaneamente e em tempo real. Essas são informações que podem ser acessadas em qualquer lugar e em quaisquer aparelhos eletrônicos ligados à rede - nasce, então, a sociedade do conhecimento.

Junto à sociedade do conhecimento, nasce uma necessidade de adequação de uso dos meios eletrônicos: além de termos acesso à internet, temos que ter acesso àquela rede social, àquele grupo midiático e, sobretudo, precisamos buscar relevância naquilo que vamos partilhar para sermos aceitos naquele nicho, ou seja, nós, cidadãos deste "novo mundo", precisamos produzir conteúdo relevante para podermos "fazer parte". Tal necessidade chamaremos de democratização do conhecimento.

Pensemos em nossos alunos. Eles são inseridos em um contexto escolar diferente daquele que estávamos acostumados há algumas décadas atrás. Por isso, eles necessitam desenvolver habilidades e competências diferentes daquelas que nós tivemos de desenvolver em nossos anos escolares. O século XXI exige que o aluno tenha a capacidade de fazer acordos, que tenha algo a partilhar e que obtenha a habilidade de interpretação e compreensão de dados.

Antes deste modelo (sociedade do conhecimento) acontecer, não se tinha acesso à internet. Nós, enquanto professores, pedíamos os dados - por exemplo, datas de início e fim de cada escola literária, principais obras de determinado autor, nomes das principais obras literárias em determinado momento, nomes de reinos e filos no caso da área de ciências etc - o aluno tinha de saber esses dados específicos. No contexto atual, os alunos não precisam memorizar estes dados porque estão com qualquer celular em rede eles conseguem acessar tais informações. 
Por isso, há um grande desafio para as escolas: adaptar-se à nova realidade da sociedade do conhecimento, não apenas de informação. Estamos diante de uma passagem de um tipo de conteúdo que era apenas banco de dados para uma análise de conteúdo móvel, haja vista que tudo está mudando instantaneamente. Para isso, o aluno precisa, então, ter a capacidade de analisar, pensar, interpretar, compreender e partilhar os dados obtidos. Este movimento é completamente inovador, as escolas não estão sabendo lidar com isso. Portanto, todos estamos no processo de reinvenção dentro de nossos saberes.

Michel Foucault, introduz a ideia da morte do autor. Se você é capaz de produzir algo significativo enquanto pessoa, aquilo que você acabou de produzir deve ser compartilhado porque você é a fonte. Já que você produziu algo inicial, também é capaz de produzir infinitamente outras coisas. Esse é o seu poder, sua capacidade de produzir de forma móvel e viva o seu conteúdo. O conteúdo não pode ser monopólio de ninguém, do contrário, teremos a exclusão do saber.

Aliás, há várias maneiras de construção do conhecimento humano. Para chegarmos ao conhecimento do mundo ou do sujeito (homem) precisamos da linguagem como objeto. A linguagem está entre as coisas e as palavras e o autor passa a ter cada vez menos importância. O autor, por diversas vezes, é associado à obra, o contexto da obra está associado ao discurso de quem a elaborou e a função do autor é relevante. No entanto, não só quem escreve a obra é o autor, mas também aquele que a lê (e portanto tantos outros) e que se identifica com a teoria do autor escritor. $O$ autor escritor é um formador trans discursivo e não mais um grande inventor.

Sobre a "morte do autor" Diz Foucault,

Esta nova disposição implica o aparecimento de um novo problema, até então desconhecido; com efeito, as pessoas perguntavam-se como era possível reconhecer se um signo designava realmente o que significava; a partir do século XVII perguntar-se-á como é que um signo pode estar ligado ao que significa ... A profunda interdependência da linguagem e do mundo acha-se desfeita. O primado da escrita é suspenso. Desaparece então essa camada uniforme em que se entrecruzaram indefinidamente o visto e o lido, o visível e o enunciável. As coisas e as palavras vão separar-se. O olho será destinado a ver, e a ver apenas; o ouvido, apenas a ouvir. O discurso terá então por objetivo dizer o que é, mas já não será coisa alguma do que diz. (Foucault, 2007, pp. 67-68)

Ao autor é designado a incumbência de articular diversos discursos, legitimá-los e atribuir-lhes uma certa unidade de escrita. Assim, uma vez que a função do autor é produzir efeitos discursivos (de controle e interdição) e, além disso, conferir legitimidade, 
o autor está condenado à morte juntamente com o sujeito que lhe dá suporte. Com a morte do autor, passamos a desempoderar o sujeito criador que, até então, detinha todo o poder do conhecimento.

Poder e conhecimento possuem um entrelaçamento de dependência. Se buscarmos na história, veremos que a relação de poder com quem detém o conhecimento sempre se fez presente. No Egito, quem tinha poder social era o Rei - Faraó. Na igreja, o detentor do poder são os padres, com o passar do tempo, observa-se que quem têm o poder do conhecimento são as universidades - cria-se, então, o centro de poder, não o de saber.

Hodiernamente, a internet está democratizando o saber, o que causa medo a quem tem o poder. Neste contexto midiático, quem tem mais valor? Quem produz um conteúdo. Desta forma, o conteúdo, em si, perde o valor e se passa a valorizar quem o produz e propaga.

O que precisamos fazer dentro de nossas ações educacionais? Criar e não reproduzir apenas. Liderar é pensar. Ao retornarmos aos padrões empresariais de três décadas notamos que quanto mais máquinas o empresário tinha, mais ele produzia/fazia dinheiro. Hoje, o empresário tem de ter talento, mas para se ter talento é preciso ter criatividade e liberdade. Nesse viés, Moran (2004) afirma que os cursos têm de trocar o foco do conteúdo para o foco da construção do conhecimento e interação. No entanto, esta prática encontra muitos obstáculos, uma vez que:

\footnotetext{
A sociedade precisa de pessoas inovadoras, que se adaptem a novos desafios, possibilidades, trabalhos, situações. É muito difícil ser criativo e empreendedor porque os professores foram preparados para repetir informações, fórmulas, procedimentos. Por isso precisamos trabalhar tanto os professores como os alunos. Sensibilizar e capacitar os professores para ações inovadoras, para tomar mais a iniciativa, para explorar novas possibilidades nas suas atividades didáticas, na sua carreira, na sua vida.” (Moran, 2004)
}

Hoje no Brasil, o acesso à internet é quase que universal. Segundo pesquisas do Cetic.com, $89 \%$ da população de 9 a 17 anos é usuária de internet no Brasil, o que equivale a 24,3 milhões de crianças e adolescentes conectados. $O$ acesso à internet não é o problema. A grande questão é que a maioria dos brasileiros não possui um nível educativo e cultural para atuar através da internet, não possui a capacidade de análise, interpretação e reprodução de dados. Assim sendo, podemos concluir que a questão da exclusão digital se deve à educação, ao sistema educativo. Castells disserta que "um país educado com 
internet progride. Um país sem educação utiliza a internet para fazer estupidez". (Castells, 202I)

\section{O PROCESSO DE INCLUSÃO DIGITAL}

A tecnologia é colocada cedo na vida dos espécimes humanos. Faz-se comum enxergar crianças navegando com singeleza por plataformas de compartilhamento de vídeos ou maiores redes de streaming. E o mais curioso: sem serem alfabetizados ou com letramento mínimo.

Os meios educativos são os espaços de inclusão mais amplamente identificados para os "nativos digitais": indivíduos com fluência e singeleza na navegação na rede disponível na internet. Outrossim, faz-se razoável refletir sobre como a adoção de produtos técnicos científicos é capaz de aproximar o aluno(a) do condicionamento e abstração de conteúdos e motivar o engajamento nas aulas com a inclusão digital nas unidades escolares (Pischetola, 2019).

A inclusão digital nas unidades escolares de educação infantil necessita ser usada com parte do Plano Político Pedagógico para prometer a operacionalização de qualificações e qualidades técnicas das crianças. Ou seja, a inclusão digital nas unidades escolares deve melhor acrescentar ao trabalho do educador e ao condicionamento e abstração de conteúdo dos alunos(as).

Com o advento do Covid-ı, variados resultados negativos à saúde, economia e educação foram universalmente originadas. Além dos impactos nos mais variados setores da sociedade, igual reinvento também sofreram as atividades nas unidades escolares públicas e privadas nos níveis de ensino. Isso fez a inclusão digital nas unidades escolares receber grande evidência na vida de profissionais de ensino, alunos(as) e familiares, que precisaram se acostumar com o uso de produtos técnicos científicos a fim de que a educação não parasse.

Nesse momento, os discentes e educadores tiveram que adotar aulas disponíveis na internet, Ambiente Virtual de Aprendizagem (AVA) e diferentes meios. É consenso que a inclusão digital nas unidades escolares fez evoluírem a procura por ensino híbrido e a implantação da metodologias ativas, tais como a sala de aula invertida (Denise Pletsch, Corrêa Pitanga de Oliveira \& Capucho Colacique, 2020) 
Conforme Oliveira (202I), a inclusão digital nas unidades escolares é capaz de estar correlacionada com o ensino híbrido, porque a metodologia possui enquanto objetivo juntar componentes presenciais e em dígitos. Outrossim, a necessária valorização do aluno(a), que obtém independência e pratica o condicionamento e abstração de conteúdos colaborativos.

Nesse viés, percebe-se que a inclusão Digital é o nome aferido ao desenvolvimento da democratização do amplo acesso aos conhecimentos técnicos da informação, de um modo a dar segmento a inclusão de todos no mundo digital como aparato instrumental de edificação e exercício da condição de cidadão.

Conforme Pischetola (2019), as bases do projeto de inclusão digital por parte da educação devem estar acondicionadas na promoção da Tecnologia da informação enquanto forma de fazer nascer trabalho e renda à população, e mais que isso, alargar o desempenho de estudo dos discentes em fase educacional, tanto ao ensino médio quanto para discentes do ensino fundamental. Importante frisar que a customização do projeto é indispensável, observado que, cada região ou território, têm originalidades e carências específicas, afinal sabemos que nosso país é dotado de múltiplas realidades.

Pelo território brasileiro e mundo afora, atentam-se projetos de inclusão digital que, na realidade, não passam de salas de informática com uso de programas de nivelamento e, além disso, tais salas se percebem paradas ou sucateadas, mesmo depois de maiores investimentos (Bonilla, 2009). É importante frisar que um projeto de Inclusão Digital que deu certo no Sudeste é capaz de não ser eficaz em Curitiba, Londrina ou Piraquara, pois essas qualidades específicas e problemas são diferentes de região para região.

Dessa forma, a educação deve incluir digitalmente o cidadão, aluno(a) ou educador, não traduz só pelo amplo acesso a informática ou amplo acesso à rede online, mas quando são averiguadas adequações com o uso adaptado da tecnologia da informação (Denise Pletsch, Corrêa Pitanga de Oliveira \& Capucho Colacique, 2020).

Uma das alternativa viáveis seria o uso de produtos de código aberto (gratuitos), nos quais os docentes podem dialogar com diferentes discentes de qualquer lugar (o que por si só gera uma inclusão social), adquirir respostas a um problema matemático, estudar em grupos disponíveis na internet, condução disciplinar síncrona, dentre outros múltiplos fatore positivos. 
Ademais, a inclusão digital total, acontece quando conseguirá ser notado um quadro de melhora, isto é, de indivíduo, de nicho social ou de uma comunidade, com o uso adaptado da tecnologia da informação (Corrêa Gomes Silveira, Marques Luiz, Xavier Guterres, Fernando da Silva Mendes \& Otoni Meireles Ribeiro, 2020).

Não obstante, Oliveira (2021), também nos diz que a inclusão digital percebe-se em um campo amplo de investigação e produção científica, que assemelha não estar indicativos de término desta novidade, destacadamente quando se alia a mesma outro bem mais atual e desafiante que é observada enquanto a apresentação desses conhecimentos técnicos no ambiente educativo, aceitando a democratização dos conhecimentos técnicos.

É válido ressaltar que pôr um computador na mão dos indivíduos ou vendê-lo a um valor acessível ou abastecer amplo acesso a rede não significa, necessariamente, inclusão digital. Afinal, Projetos de Inclusão Digital promovem geração de trabalho com os multiplicadores locais e inclusão social direta, cujos impactos são notados em pequeno prazo.

Nesse viés, é válido refletir: quanto custa um aluno(a), antes perdido nas substâncias e sem referência ou concepção, volta à escola e acha que é capaz de buscar trabalho, vender serviços e utensílios/produtos com um click no celular? (Denise Pletsch, Corrêa Pitanga de Oliveira \& Capucho Colacique, 2020).

O momento seguinte terá de ser a habilitação dos educadores, tendo como foco dar quesitos ao uso de tal aparelhagem de investigação, geração de trabalho, renda, informação, desenvolvimento educativo, econômicos, fazer nascer e coordenar empreendimento à rede mundial de PCs e fazer multiplicações o saber seguidamente aos discentes. Outrossim, (...) damos a condição ao educador de ter uma renda extra, especialização e legitimação.

Com a habilitação dos educadores, daremos princípio a Inclusão Digital dos discentes, em que estes poderão fazer uso da informática como aparelhagem de busca, investigação, informação, alargando e tornando dinâmico seu conhecimento em frente às matérias educacionais e como fazer nascer e coordenar empreendimento dando grande evidência ao empreendedorismo digital (Corrêa Gomes Silveira, Marques Luiz, Xavier Guterres, Fernando da Silva Mendes \& Otoni Meireles Ribeiro, 2020). 


\section{INOVAÇÃO DAS TDIC'S}

As TDICS são compreendidas através da visualização de diversos dispositivos como os mais comuns smartphone, celular, tablet, laptop, entre outros, adaptamos às novas tecnologias da informação e de comunicação, como meios tecnológicos que interagem através de seres humanos máquinas, aos quais tem estreitado as relações da sociedade na busca do conhecimento, formatando novas culturas e novos comportamentos e possibilitando a resolução de problemas, que serve para facilitar a nossa dinâmica do dia a dia, uma vez que as mesmas já se fazem presente mesmo que ainda não compreendida em sua totalidade e utilidades.

Para Soares e Alves (2008), as inovações tecnológicas estão relacionadas ao uso do conhecimento sobre novas formas de produzir bens e serviços no que se refere aos serviços educacionais atualizados. As autoras ainda nos remete ao entendimento que: $O$ aprendizado contínuo e interativo no processo de inovação deve ser intensificado criandose uma capacitação adequada por meio do ensino constante para se compreender e promover mudanças.

Agindo assim é que, estaremos conduzindo o ensino e aprendizagem sugerido pela era tecnológica. Diante disso, podemos dizer que é imprescindível a integração das TDICs, como parte fundamental na educação, mesmo observando algumas resistências no uso, muito mais por parte dos professores do que pela gestão educacional como um todo, uma vez que já se observa uma busca pela adaptação nos ambientes educacionais.

As Tecnologias da informação e Comunicação surgiram basicamente em meados da década de I970, avançando numa grande proporção a partir de 1990 e, deste então, têm sido indispensáveis e de grande relevância no dia a dia das pessoas e das instituições educacionais por sua gigantesca contribuição para resolver uma diversidade de situações e problemas, tanto na vida pessoal e profissional.

Nesta perspectiva não podemos considerar a intervenção das tecnologias no processo de ensino e aprendizagem como algo tão novo, o que vem acontecendo é a morosidade nas adaptações do uso dela na educação de forma consistente como parte ou seja, ocorre que ela está sendo propagada o tempo todo como algo mirabolante, quanto que na verdade a tecnologia tem seu papel de inovar a cada dia. 
Para Lima, Andrade e Damasceno [s.d.] quando pensamos em tecnologia a favor da educação, devemos vê-la como um conjunto de ferramentas que proporciona ao professor várias vantagens, como a praticidade para adquirir as informações necessárias à construção do conhecimento ao longo da sua vida. A soma dos métodos antigos com as novas descobertas linguísticas e tecnológicas vem dando aos professores, que a aderiu, suporte necessário no desenvolvimento das suas atividades.

As TDICs, no contexto globalizado têm permitido o indivíduo participar das inovações do mundo, pois elas são responsáveis por trazer informação e conhecimento, permitir o pensamento da criticidade e da superação do novo. E, logicamente, essa descoberta deve estar condizente com o que se aprende e se ensina também no contexto escolar.

Para Santo e Moura (2020) este processo tecnológico não oferece, tão-somente, maneiras mais vivas para trabalhar os teores abordados nas salas de aula. Elas promovem inovações nas formas de instruir-se, permitindo, aos estudantes, assumirem um caráter muito mais crítico e influente no processo de incremento educacional. Neste contexto é sabido que as novas tecnologias, sincronizadas a capacidade técnica dos envolvidos na educação é que provavelmente impulsiona a produção e transmissão de conhecimento.

Para Marçolla (2019, p.27) a comunicação, como sabe, alterou-se diante das evoluções tecnológicas. As pessoas também mudaram as formas de relacionamento, inserindo os meios de comunicação como protagonistas desse cenário que vem se desenhando a todo instante

Podemos dizer que, no século marcado pela inclusão das novas tecnologias, é que recai o papel essencial para enriquecer a produção de conhecimentos, bem como fomentálos na sociedade contemporânea. Servem também para sincronizar alunos e professores numa linguagem coerente que potencializa a participação na aprendizagem.

Neste contexto tecnológico, nasce também os aspectos paradoxais no que diz respeito ao acesso das TDICs, que, no primeiro momento ao compará-los, certamente parecerão contraditórios, mas que representam uma multiformidade.

Em outras palavras, alunos e professores estão conectados a ponto de não saberem viver sem esse acesso quer seja por um dia, porém é notória a finalidade do uso, haja vista 
que, quando requerido para ensinar e aprender de forma sistemática, existem resistências e essas são caracterizadas por gerações contextualizadas e designadas por terminologias.

Para Ebert, Possamai e Simon (2017,p.102-102), entre nativos e imigrantes digitais existe uma enorme diferença, pois os nativos têm acesso a todas as formas de tecnologia logo nos primeiros anos de vida, enquanto os imigrantes necessitam se adaptar a este novo universo que está à sua disposição.

Em relação com as TDICs, os autores ainda citam algumas das diversas características dos nativos digitais como: são digitalmente alfabetizados, conectados, imediatista, experimentadores sociais, etc. Por outro lado, a geração dos imigrantes têm buscado constante adaptação e capacitação.

Haja vista que a tecnologia, por si só, nada fará, mas que, atrelada ao pensamento crítico, pode atender as necessidades demandadas na educação, as TDICS são tidas como ferramentas indispensáveis para atender ao aluno do século XXI. Sendo comprovada por diversos atores (inclusive em minha própria práxis docente), através da experiência na educação à distância. Docentes conectados com as TDIC's têm percebido que integrar os diversos aparatos tecnológicos em todos os níveis da educação facilita o ensino, aperfeiçoa a aprendizagem, promove a criticidade, a proatividade e a dinamicidade discente, além de tornar a práxis pedagógica mais atraente.

\section{CAUSAS E CONSEQUÊNCIAS DA FALTA DE ACESSO ÀS NOVAS TECNOLOGIAS}

Vivemos a consolidação de uma nova estrutura econômica e social intimamente ligada à tecnologia: a sociedade da informação. A globalização e as novas tecnologias de informação e comunicação trouxeram benefícios mais amplos para a sociedade. De acordo com os dados a seguir sobre o uso global da Internet em 2020, há mais de quatro bilhões de usuários da Internet no mundo representando $58,7 \%$ dos usuários globais da Internet. A tecnologia da informação agora se tornou uma característica rotineira da sociedade global e as estatísticas mostram que todos os continentes usam a Internet. 


\section{Internet Users Distribution in the World - 2021}
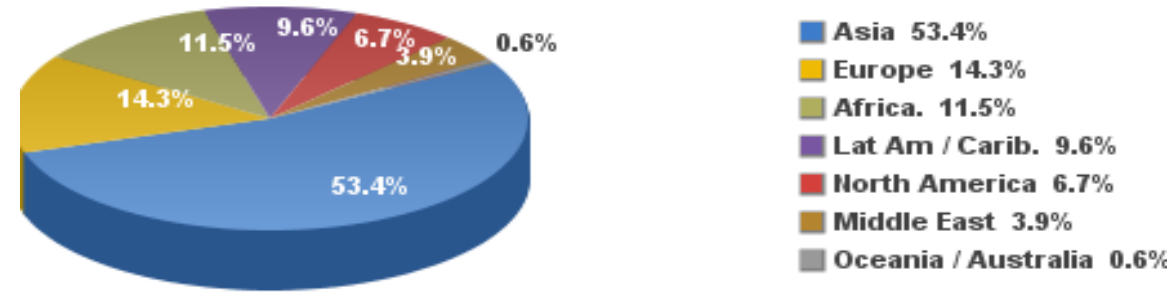

Fonte: https://www.internetworldstats.com/stats.htm

Os dados mostram o distanciamento tecnológico entre as nações, embora as redes de Internet tenham alcançado praticamente em todos os países. No entanto, de acordo com o Relatório do Estado da Banda Larga 2019 preparado pela Comissão de Banda Larga, quase metade da população mundial não tem acesso a esses recursos. Nesse ponto, é conveniente combinar o acesso à Internet e a alfabetização digital. Para Harari (2018), ser excluído da Internet significa ser socialmente excluído no século XXI. Espera-se que a Internet e outros avanços tecnológicos sejam ferramentas para remover barreiras entre nações e classes, mas podem estar aumentando a desigualdade:

Nas últimas décadas foi dito às pessoas em todo o mundo que o gênero humano está no caminho da igualdade, e que a globalização e as novas tecnologias nos ajudarão a chegar lá mais cedo. $\mathrm{Na}$ verdade, o século XXI poderia criar a sociedade mais desigual na história. Embora a globalização e a internet representem pontes sobre as lacunas que existem entre os países, elas ameaçam aumentar a brecha entre as classes, (...). (Harari,2018. p.io2)

A segregação digital sempre foi atribuída ao subdesenvolvimento. Nesse viés, devemos considerar as seguintes causas: falta de acesso aos recursos de informática, altos preços de equipamentos, falta de compreensão de uso ou incapacidade de usar a infraestrutura, Tais fatores podem levar aos seguintes tipos de exclusões: de uso, de qualidade de uso e de acesso.

A falta de acesso às novas tecnologias priva parte da população dos recursos necessários ao desenvolvimento e à criação de riqueza, constituindo uma espécie de carência e segregação social. No decorrer da pandemia de COVID-I9, frequentemente vemos essa situação. Muitos alunos e funcionários têm dificuldade no trabalhar remoto e assistir às aulas online. Podemos listar barreiras de aprendizagem e conhecimento, falta de comunicação e isolamento, aumento das disparidades sociais e discriminação de gênero como os principais efeitos da falta de acesso às novas tecnologias digitais. 
Os Objetivos de Desenvolvimento Sustentável consideram a redução da exclusão digital como fator de desenvolvimento dos países e, por isso, iniciativas para promover a aquisição de tecnologia têm sido implementadas em diversos lugares. Aqui, mencionamos algumas das mais relevantes: Projetos de alfabetização digital, Free Basics, acordo para uma Internet acessível (A4AI) na África, Ásia e América Latina, Starlin. É justamente por causa das muitas realidades dos país que os desafios se complicam. As políticas públicas elaboradas para as cidades podem variar de país para país e carecem de uma política contínua de inclusão digital.

A pesquisa TIC Domicílios de 2019 realizada em 23.490 domicílios brasileiros, descreveu dados sobre desigualdade digital. De acordo com esta pesquisa 26 milhões de brasileiros não podem acessar a Internet, 20 milhões de lares (28\%) não têm ligação à Internet. 35 milhões de pessoas nas áreas urbanas (23\%) e 12 milhões de pessoas (47\%) nas áreas rurais ainda não têm acesso à Internet. Além disso, 58\% dos brasileiros só usam o celular para navegar na internet e esse percentual chega a $85 \%$ nas categorias mais pobres onde apenas $14 \%$ das famílias têm computadores.

Embora os dados da pesquisa TIC Domicílios tenham sido recolhidos durante o período anterior à propagação da pandemia, os seus dados revelam como as restrições de acesso afetam os segmentos mais vulneráveis da população. Neste período de isolamento social, mais crianças em idade escolar não conseguem aceder à Internet, sendo as famílias vulneráveis mais afetadas.

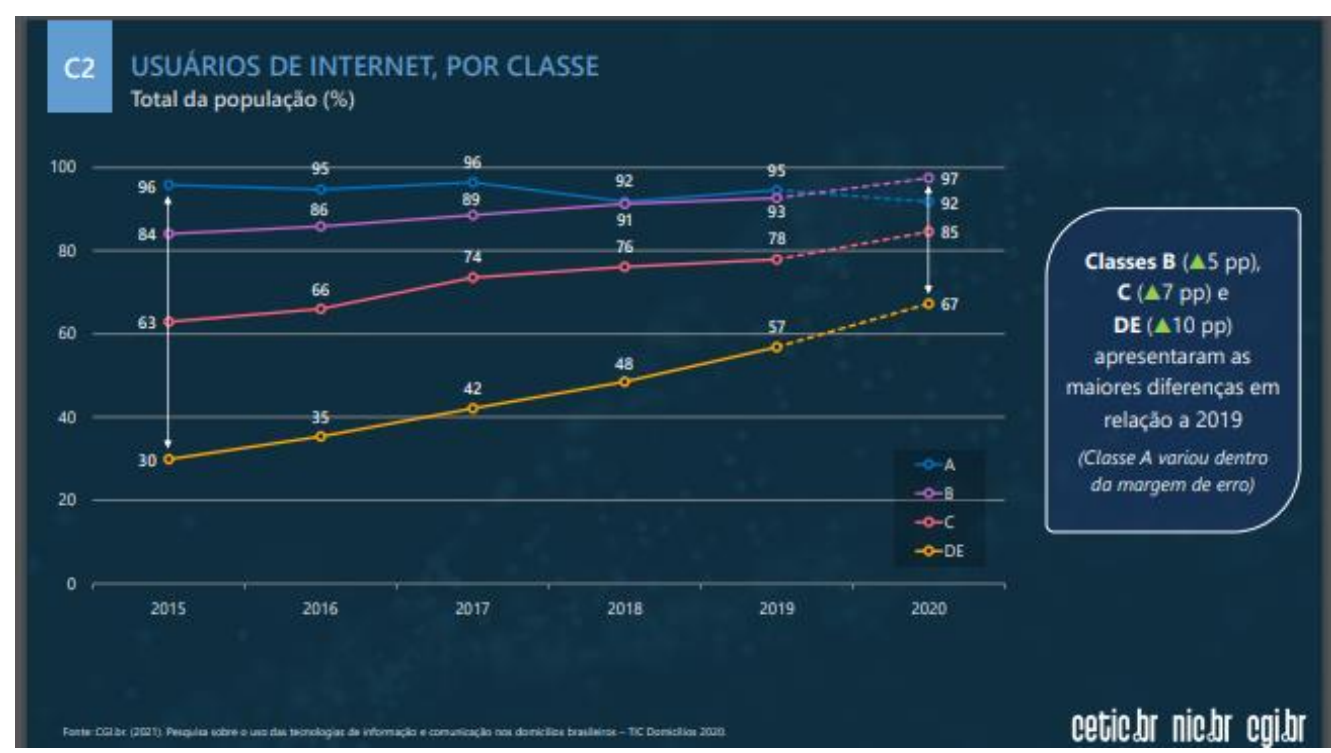

Fonte: file://C:/Users/PG/Downloads/tic_domicilios_2020_coletiva_imprensa.pdf 
Em um mundo interconectado, as barreiras digitais significam também impedir que determinados segmentos da sociedade integrem novas formas de aprendizagem e trabalho. O TIC Domicílio revelou ainda que apenas 3 em cada io pessoas das classes $\mathrm{D}$ e utilizam a Internet para atividades relacionadas com a educação.

Com isso, verifica-se que a disponibilização de acesso à Internet em espaços que deveriam atuar como mecanismos de inclusão digital na realidade reforça a elevada discriminação que se observa no uso privado domiciliar. Se as políticas públicas de desenvolvimento digital (nos estabelecimentos públicos de ensino ou nas comunidades) tiveram a intenção de incluir os setores com escassas ou nulas condições de acesso à Internet ou ainda de democratizar as condições de uso, o resultado parece ser reforçar mais a concentração existente nos grupos com melhores condições econômicas e sociais. (Waiselfisz,2007.p 23)

Segundo o Marco Civil da Internet do Brasil, todos têm o direito de usar a Internet (inclusive famílias em extrema fragilidade social). Além disso, de acordo com o conteúdo do Conselho de Direitos Humanos das Nações Unidas (Resolução A / HRC / C / L.2o.), O reconhecimento da difusão da conectividade e a ênfase no acesso à informação na Internet proporciona um grande número de oportunidades, sobretudo para discentes da educação gratuita.

\section{DESDOBRAMENTOS PARA O EXERCÍCIO PLENO DA CIDADANIA DENTRO DA SOCIEDADE DO CONHECIMENTO}

Pensar em cidadania na sociedade atual exige que se reflita sobre o processo de Educação por que passam os cidadãos. A partir dessa relação de causa e consequência entre a qualidade da educação e o nível de cidadania de um indivíduo, muito se fala sobre uma formação autônoma e integral do aluno. Esse diálogo é importante por indicar que o aluno precisa entender o mundo e, por conseguinte, desenvolver as habilidades de cumprir os seus deveres e reivindicar os seus direitos. Nesse sentido, cabe definir o que se entende por cidadão no contexto histórico atual.

De acordo com Varela (1999), o conceito de "cidadão", pode ser etimologicamente entendido como um membro livre, inserido em uma determinada cidade. Seja por origem, ou adoção, esse indivíduo assume um conjunto de raízes culturais, políticas e sociais. Um cidadão movimenta-se em um dado conglomerado sociopolítico e econômico, de modo a dinamizar o complexo cultural. Essa dinamização pressupõe o acesso e a aquisição de conhecimentos e a consequente aplicação desses conceitos com vistas à construção e manutenção de condições de vida aos membros da sociedade. 
Entende-se a sociedade de conhecimento, segundo Vitro (1993), como uma sociedade em que a informação transforma-se em conhecimento partilhado e permite que sejam desenvolvidos mecanismos que estimulem a capacidade das pessoas de criar e aplicar tais conhecimentos. De acordo com o pesquisador, a informação contribui tanto para a produção e distribuição de informação (o que pode ser entendido como uma atividade econômica), quanto com a melhoria da produtividade e da ampliação da qualidade de bens e serviços dada a aplicação do conhecimento.

Autores como Miranda (1996), refletem que a simples existência de um rol variado de informações, nem mesmo o acesso facilitado à informação na sociedade, não garante que seus cidadãos detenham de fato o conhecimento e o desenvolvimento esperado. Isso porque não basta o acesso a imensos repertórios ou arquivos de dados, enquanto fontes de conhecimento, como a internet nos proporciona. Urge que haja mais do que o mero "download" de informações. Espera-se que a reflexão e a aplicação dos conhecimentos adquiridos possibilite que os cidadãos façam "upload" de conhecimentos, ou seja, possam contribuir e acrescentar novos conhecimentos à sociedade. Para tanto, formação escolar deve fornecer os subsídios necessários: as habilidades de comunicação e criatividade são exemplos de aspectos indispensáveis à efetivação da cidadania. Nesse sentido, Oriá (1997) indica que a escola exerça papel precípuo na formação de cidadãos inseridos na sociedade do conhecimento.

A educação para a cidadania deve ultrapassar o meramente conceitual e atingir a efetiva educação comprometida com a ação social responsável. Isso porque "a formação científica para a cidadania se justifica pela necessidade de permitir a participação dos indivíduos em decisões de natureza tecnocientífica" (Toti, Pierson e Silva, 2009, p. 8-9).

Enquanto há aqueles que vivem à margem da sociedade, a escola deve ser o lugar em que a socialização do conhecimento reflita sobre o significado de "ser cidadão no Brasil”. De acordo com Sacavino, do ponto de vista da igualdade em qualidade de vida e direitos humanos, democracia desenvolvida é sinônimo de sociedade inclusiva e abrangente.

Trata-se de um processo histórico que se conquista e se aperfeiçoa conjuntamente com o desenvolvimento da lógica democrática. Reconhecemos que, historicamente, no conceito de nossas sociedades, esse processo não se tem dado predominantemente em forma inclusiva e igualitária, e sim, pelo contrário, vem sendo ainda mais comprometido com as políticas neoliberais. (SACAVINO, 200o, p. 39) 
Nesse contexto, Masuda (1982) entende o perfil dessa sociedade emergente do conhecimento como aquela em que a produção de valores informacionais e, consequentemente, intangíveis, substitui os valores tangíveis. Essa sociedade da informação deve configurar-se como uma comunidade voltada para o benefício social de forma voluntária. Isso indica que a qualidade de vida da população deve melhorar e, por conseguinte, deve-se reduzir o desnível social entre ricos e pobres, conforme postula Romer (1999).

Entende-se, pois, que o papel da escola na formação do cidadão para atuar de maneira plena na sociedade do conhecimento historicamente seja produzir conhecimentos significativos e, portanto, preparar os alunos para a gestão efetiva de saberes e para a futura construção de novos conhecimentos. A garantia da cidadania demanda que sejam assegurados os direitos de acesso à informação e à educação aos indivíduos. Esse acesso à educação de qualidade pode implementar o futuro, proporcionando mais do que sobrevivência no interior de uma tão sociedade tão competitiva como a contemporânea. Afirma-se, por fim, que o acesso à sonhada educação de qualidade seja capaz de proporcionar a desejada dignidade aos cidadãos.

\section{CONSIDERAÇÕES FINAIS}

É inegável que a pandemia proporcionou perdas, sofrimentos e tragédias. No entanto, alguns de nós, como seres resilientes que somos, conseguimos observar o ganho que obtivemos ao avançarmos anos luz no entendimento de que não mais podemos retroceder ou permanecer utilizando as mesmas táticas ultrapassadas pertencentes aos séculos anteriores.

Uma postura docente que zele pela liderança mediadora educacional, calçada na intencionalidade pedagógica e em consonância com a revolução tecnológica, tem o poder de promover a homeostase, proporcionar consciência coletiva, desenvolver valores humanos, capacitar profissionalmente, derrubar paradigmas e transformar realidades desprivilegiadas.

Assim, é imperativo que a educação desenvolva processos que deem aos alunos a possibilidade de desenvolverem as habilidades e competências necessárias para que sobrevivam ao meio em que serão inseridos. Cabe à escola criar estratégias que desenvolvam a autonomia, o pensamento crítico, a criatividade e meios disruptivos para 
aprender diante de uma perspectiva tecnológica e com acesso à informação, pois este é o caminho para a democratização do conhecimento.

Podemos aliar e integrar as TDICs (tecnologias digitais de informação e comunicação) às práticas pedagógicas em sala de aula. No entanto, apenas ter conhecimento técnico a respeito das tecnologias não é o bastante para integrá-las à educação. Há grande necessidade de planejamento pedagógico e acadêmico aliado ao incrível e complexo processo de educação. Assim, a escola precisa mudar, repensar sua postura e incentivar os estudantes a participarem, a se envolverem em novas descobertas, a resolverem problemas a partir de investigações próprias, trabalhar o protagonismo e o empreendedorismo.

No entanto, embora o desenvolvimento contínuo deva ser buscado, a reformulação do cenário educacional brasileiro deve ser proporcionado desde os pontos basilares, através da valorização do ensino pelos detentores do poder, que devem não só fazer exigências de aprimoramento, mas também prover capacitação para a viabilização transformadora do chão da escola, seja ele em espaço físico ou virtual. Nesse sentido, com o cumprimento real das prerrogativas constitucionais, os poderes executivo e legislativo devem andar em consonância para exercerem e fiscalizarem o direito de uma formação de qualidade para todos, que proporcione dignidade, igualdade, participação e inclusão.

\section{REFERÊNCIAS BIBLIOGRÁFICAS}

Bonilla, Helena Silveira (2009). Inclusão digital nas escolas [Ebook] (Ist ed., pp. I-I5). João Pessoa: Editora universitária da UFPB. Retrieved from http://www.universidadenova.ufba.br/twiki/pub/GEC/RepositorioProducoes/artigo_bo nilla_mesa_inclusao_digital.pd.

Castells, Manuel: "um país educado com internet progride; um país sem educação usa a internet para fazer "estupidez" | GZH. (2015). Retrieved Io October 2021, from https://gauchazh.clicrbs.com.br/geral/noticia/2015/05/manuel-castells-um-pais-educadocom-internet-progride-um-pais-sem-educacao-usa-a-internet-para-fazer-estupidez4762171.html\# 
Corrêa Gomes Silveira, L., Marques Luiz, J., Xavier Guterres, L., Fernando da Silva Mendes, L., \& Otoni Meireles Ribeiro, L. (2020). Tecnologias Assistivas no contexto da acessibilidade e mobilidade: possibilidades de inclusão digital de autistas na educação a distância. Em Rede: Revista De Educação A Distância, (7), 6I-73. Retrieved from https://www.aunirede.org.br/revista/index.php/emrede/article/view/539

Denise Pletsch, M., Corrêa Pitanga de Oliveira, M., \& Capucho Colacique, R. (2020). Apresentação-inclusão digital e acessibilidade: desafios da educação contemporânea. Revista Docência E Cibercultura, (4), 13-23. Retrieved from https://www.e-publicacoes.uerj.br/index.php/re-doc/article/view/50573

Ebert, Luis Augusto. POSSAMAI, Cleide Tirana Nunes. SIMON, Vanessa Pereira. Perspectivas Profissionais. Indaial: UNIASSELVI, 2017.

Foucault, M. and Muchail, S., 2007. As palavras e as coisas. São Paulo: Martins Fontes, pp

Harari, Yuval Noah. 2I lições para o século 2I. I das Letras.

Jenkins, H. Cultura da Convergência. São Paulo: Aleph, 2008.

Jesus, Saul Neves de. Estratégias para Motivar os Alunos. Educação, Porto Alegre, Jan/Abr. 2008.

Lei do Marco Civil da Internet no Brasil https://www.cgi.br/lei-do-marco-civil-dainternet-no-brasil/ acesso em I8/10/2021.

Lima, Jeane de Oliveira. ANDRADE, Maria Nascimento. DAMASCENO, Rogério José de Almeida. A Resistência Do Professor Diante Das Novas Tecnologias.O uso das novas tecnologias na educação, segundo uma visão nova do processo ensinoaprendizagem.Disponível em:www.meuartigo.brasilescola.uol.com.br/educacao/aresistencia-professor-diante-das-novas-tecnologias.htm. acessado em I8-IO-202I 
Masuda, Yonegi. A sociedade da informação como sociedade pós-industrial. Rio de Janeiro: Ed. Rio, 1982.

Miranda, A. Globalización y sistemas de información: nuevos paradigmas y nuevos desafíos. In: Conferência regional políticas y estrategias para la transformaciona de la educación superior en amercia latina y el caribe. La Habana, 1996.

Moran, J., 2004. A contribuição das tecnologias para uma educação inovadora. 4th ed. [ebook] Itajai: Contrapontos, pp.347-356. Available at: 〈https://siaiap32.univali.br > article〉 [Accessed I4 October 202I].

Morçolla Rosangela . Teoria da Comunicaçoa - Indaial: Uniasselvi, 2019

ORIÁ, José Ricardo. Educação, cidadania, diversidade cultural. Humanidades. Brasília, v. 43, 1997 .

Prudêncio, Erivelto Alves; Carvalho, Jairo de; Ferreira, José Luis. As Novas Tecnologias de Informação e Comunicação e o Sistema de Gerenciamento de Cursos Moodle. In: Formação de Professores em EAD. Maringá: Universidade Estadual de Maringá, 2007, Módulo II, Unidade 4.

Pischetola, M. (2019). Inclusão digital e educação: A nova cultura da sala de aula. Brasil: Editora Vozes.

ONU. Estudo da ONU revela que mundo tem abismo digital de gênero | ONU News https://news.un.org/pt/story/2019/II/I6937II Acesso em I2/Io/202I.

Romer, Paul. Sai o átomo, entra o bit. Economia e Negócios. Entrevista, Veja, v. 32, n. 27, 7 jul. 1999 .

Santo, Sandra Aparecida Cruz do Espírito. SILVA, Joelma Tavares da., MOURA, Giovana Cristina de.O Uso da Tecnologia na Educação: Perspectivas e 
Entraves.Disponível em:.https://www.nucleodoconhecimento.com.br/educacao/uso-datecnologia\#2-AS-CONTRIBUICOES-DA-TECNOLOGIA-NA-EDUCACAO. Datado acesso em I8-10-202I.

Sacavino, Suzana. Democracia e cidadania na nova ordem mundial globalizada. In: Candau, Vera Maria (org.), Sacavino, Susana (org.) Educar em direitos humanos: construir democracia-Rio de Janeiro: DP\&A, 2000.

Soares, Cristiane da Silva, Alves, Thays de Souza (2008) Sociedade da Informação no Brasil: Inclusão Digital e a Importância do Profissional de TI- Reflexão sobre a inclusão digital no Brasil como forma de inclusão social . Disponível em: MOnografias . brasilescola.uol.com.br. Acesso em:2I/o9/2021.

Souza Laine Moraes. Acesso à Internet é considerado Direito Humano para a ONU http://www.ohchr.org/en/NewsEvents/Pages/DisplayNews.aspx?NewsID=20223\&Lang I

http://www.lainesouza.adv.br/ : Acesso em I2/10/2021

TIC Domicílios https://cetic.br/pt/pesquisa/domicilios/ acesso em I8/ro/202I

Toti, F. A.; Pierson, A. H. C.; Silva, L. F. Diferentes perspectivas de cidadania presentes nas discussões atuais em defesa da abordagem CTS na educação científica. In: VII Encontro Nacional de Pesquisa em Educação em Ciências. Florianópolis, 2009.

Valente, Jonas. Agencia Brasil. https://agenciabrasil.ebc.com.br/economia/noticia/201909/quase-metade-do-planeta-ainda-nao-tem-acesso-internet-aponta-estudo https://broadbandcommission.org/Documents/StateofBroadbandig.pdf. Acesso em 13/10/2021 ( Referência do Relatório do Estado da Banda Larga 2019 preparado pela Comissão de Banda Larga) 
Revista Ibero- Americana de Humanidades, Ciências e Educação- REASE

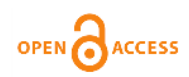

Waiselfisz, Julio Jacobo. Mapa das Desigualdades Digitais no Brasil http://www.clam.org.br/bibliotecadigital/uploads/publicacoes/1285_168o_desigdigitalbrasi 1.pdf acesso em i8/10/2021

Varla, Aida. Informação e construção da cidadania. Brasília, 1999. Ios f. (Dissertação Mestrado Ciência da Informação UnB/ CID).

Vitro, Roberto. Para uma economia do desenvolvimento baseada em conhecimento. R. Bibliotecon. UFMG, Belo Horizonte, v. 22, n. I, p. 9 a 37, jan./jun. 1993. 